\title{
Germinação de sementes in vitro e desenvolvimento de plantas ex vitro de algodãozinho-do-campo
}

\author{
In vitro seeds germination and ex vitro plants development of algodãozinho-do-campo
}

\author{
Marielle Cascaes Inácio ${ }^{\mathrm{I}, \mathrm{II}^{*}}$ Bianca Waléria BertoniI ${ }^{\mathrm{II}}$ Suzelei de Castro França ${ }^{\mathrm{II}}$ \\ Ana Maria Soares Pereira ${ }^{\mathrm{I}, \mathrm{II}}$
}

\section{RESUMO}

Este estudo teve por objetivo avaliar a assepsia, quebra de dormência e germinação das sementes de Cochlospermum regium in vitro e o desenvolvimento ex vitro de plantas dessa espécie. Na assepsia das sementes, foram utilizados benlate, hipoclorito de cálcio e ácido sulfúrico. A superação da dormência foi realizada com sementes imersas em ácido sulfúrico por diferentes períodos. Para verificar a influência do tamanho das sementes na germinação, estas foram classificadas em grandes $\left(A=34,08 \mathrm{~mm}^{2}\right)$, médias $\left(A=27,74 \mathrm{~mm}^{2}\right)$ e pequenas $\left(A=17,99 \mathrm{~mm}^{2}\right)$. No desenvolvimento de plantas ex vitro, foram utilizados substratos areia ou solo de Cerrado+esterco. Eficiente assepsia das sementes foi obtida com a utilização do ácido sulfúrico. A imersão por 146 e 144 minutos, para quebra de dormência, proporcionou maior porcentagem de germinação (63\%) e IVG (0,78) respectivamente - sem nenhuma contaminação. As sementes maiores apresentam maior IVG $(0,61)$ em relação a sementes menores. Embora o desenvolvimento das plantas em solo de Cerrado+esterco ou areia tenha sido semelhante, no primeiro substrato, as mudas mostraram-se mais vigorosas.

Palavras-chave: Cochlospermum regium, Cerrado, propagação, dormência, Cochlospermaceae.

\section{ABSTRACT}

This study was designed to conduct experiments with germination and dormancy breaking in in vitro seeds of Cochlospermum regium in vitro and evaluate the development of plants ex vitro for this species. For the sterilization of seeds introduced in vitro, were used benlate, calcium hypochlorite and sulfuric acid. The break dormancy was realized with seeds immersed in sulfuric acid for different periods. To check the influence of seed size on germination, they were classified as large $\left(A=34.08 \mathrm{~mm}^{2}\right)$, medium $\left(A=27.74 \mathrm{~mm}^{2}\right)$ and small $\left(A=17.99 \mathrm{~mm}^{2}\right)$. For the development of ex vitro plants were used sand substrate or Cerrado soil + manure. Efficient sterilization of seeds was achieved with the use of sulfuric acid. The immersion for 146 and 144 minutes, to break dormancy, showed higher germination rate and germination speed of $63 \%$ and 0,78 respectively - with no contamination. Larger seeds germinated faster (0.61) than smaller ones. Though ex vitro development of plants cultured in both substrates was similar, plantlets cultured in soil + manure were more vigorous.

Key words: Cochlospermum regium, Cerrado, propagation, dormancy, Cochlospermaceae.

\section{INTRODUÇÃO}

Cochlospermum regium, conhecida popularmente por algodãozinho-do-campo, é uma espécie endêmica do Cerrado, encontrada preferencialmente em locais modificados pelo homem, como estradas, ferrovias, entre outras (POPPENDIECK, 1981). É considerada espécie pioneira por ocorrer tanto em áreas abertas como em áreas perturbadas (COELHO et al., 2008). O extrato das raízes é utilizado, etnofarmacológicamente, para várias indicações, mas principalmente para infecções do ovário e do sistema reprodutivo feminino (TRESVENZOL et al., 2006; SOUZA \& FELFILI, 2006).

'Programa de Pós-graduação em Agronomia (Horticultura), Faculdade de Ciências Agronômicas, Universidade Estadual Paulista "Júlio de Mesquita Filho" (UNESP), Botucatu, SP, Brasil.

"Departamento de Biotecnologia de Plantas Medicinais, Universidade de Ribeirão Preto (UNAERP), 14096-900, Ribeirão Preto, SP, Brasil. E-mail: marycascaes@gmail.com.*Autor para correspondência. 
Sementes dessa espécie apresentam característica ortodoxa, por tolerarem dessecação a $-20^{\circ} \mathrm{C}$, e são consideradas dormentes devido à presença do tegumento duro que impede a permeabilidade da água (KIRIZAWA, 1981; CAMILLO, 2008). Essa característica está provavelmente relacionada ao déficit hídrico das estações de inverno e outono do Cerrado, o que faz com que as sementes de muitas das espécies presentes nesse bioma, apresentem dormência neste período e iniciem a germinação na estação chuvosa, momento em que as condições ambientais são mais favoráveis à sobrevivência da planta. Além disso, as sementes são fotoblásticas neutras e a temperatura de $25^{\circ} \mathrm{C}$ é a mais adequada para a germinação (COELHO et al., 2008).

Considerando que a espécie é coletada de forma extrativista e que não há estudos agronômicos suficientes que viabilizem o cultivo da planta em larga escala, a produção de fitoterápicos industrializados a partir de $\boldsymbol{C}$. regium é totalmente inviável até o momento.

Assim, o objetivo do presente trabalho foi avaliar a assepsia, quebra de dormência e germinação das sementes de C. regium in vitro e o desenvolvimento ex vitro de plantas dessa espécie.

\section{MATERIAL E MÉTODOS}

Frutos maduros de $\boldsymbol{C}$. regium em estado de deiscência foram coletados em locais de ocorrência natural da espécie, nos Estados do Mato Grosso, Goiás e Minas Gerais. As sementes foram beneficiadas manualmente, armazenadas em sacos de papel kraft e mantidos em câmara fria a $5^{\circ} \mathrm{C}$.

\section{- Experimentos in vitro}

Assepsia - Sementes de $\boldsymbol{C}$. regium foram submetidas a três tratamentos para avaliar a assepsia in vitro: 1) imersão por duas horas em benlate $\left(\mathrm{C}_{14} \mathrm{H}_{18} \mathrm{~N}_{4} \mathrm{O}_{3}\right) 5 \%$ e 30 minutos em hipoclorito de cálcio $\left.\left(\mathrm{Ca}(\mathrm{ClO})_{2}\right) 0,5 \% ; 2\right)$ um minuto em ácido sulfúrico $\left(\mathrm{H}_{2} \mathrm{SO}_{4}\right) 98 \%$, duas horas em benlate $5 \%$ e 30 minutos em hipoclorito de cálcio $0,5 \%$; ou 3 ) um minuto em $\mathrm{H}_{2} \mathrm{SO}_{4}$, duas horas em benlate 5\%, 30 minutos em hipoclorito de cálcio $0,5 \%$ e 40 minutos em $\mathrm{H}_{2} \mathrm{SO}_{4} 98 \%$ (PA). As sementes permaneceram sob agitação em mesa orbital à 90rpm e, quanto ao ácido sulfúrico, a imersão foi estática em capela de exaustão.

Superação da dormência - Para superação da dormência, as sementes foram imersas em $\mathrm{H}_{2} \mathrm{SO}_{4}$ $98 \%$ por $1,20,40,80,120,160$ ou 200 minutos. As sementes, antes de serem utilizadas neste experimento, permaneceram armazenadas em câmara fria por seis meses.
Influência do tamanho das sementes - As sementes foram classificadas em pequenas, médias e grandes (Figura 1A), a partir de medições de comprimento e largura com paquímetro, submetidas ao melhor tratamento de superação de dormência (120 minutos em $\mathrm{H}_{2} \mathrm{SO}_{4}$ ) e inoculadas in vitro. Antes de serem utilizadas neste experimento, as sementes permaneceram armazenadas em câmara fria por dez meses.

Todas as sementes utilizadas para as avaliações in vitro foram coletadas no mês de agosto de 2008, beneficiadas manualmente e formaram um único lote que permaneceu armazenado em câmara fria até o momento de seu uso. Após serem submetidas à assepsia e/ou exposição ao $\mathrm{H}_{2} \mathrm{SO}_{4}$, foram lavadas três vezes em água destilada e autoclavada, em câmara de fluxo laminar. A seguir foram inoculadas em cubetas de vidro contendo meio MS (MURASHIGE \& SKOOG, 1962) suplementado com $30 \mathrm{~g} \mathrm{~L}^{-1}$ de sacarose e gelificadas com 2,5 $\mathrm{g} \mathrm{L}^{-1}$ de Phytagel ${ }^{\circledR}$. Todas as sementes foram mantidas em sala de crescimento com temperatura de $25 \pm 2^{\circ} \mathrm{C}$, intensidade luminosa de $25 \mu \mathrm{Mol} \mathrm{m} \mathrm{m}^{-2} \mathrm{~s}^{-1} \mathrm{e}$ fotoperíodo é 16 horas de luz: 8 horas de escuro.

Os parâmetros avaliados foram índice de velocidade de germinação (IVG), porcentagem de germinação, presença ou ausência de crescimento de microorganismos endógeno ou exógeno entre a semente e o meio de cultura. As avaliações foram realizadas diariamente por 40 dias. Foram consideradas germinadas sementes com protrusão radicular. $\mathrm{O}$ delineamento experimental foi inteiramente casualizado, com três repetições e dez replicatas, totalizando 30 sementes por tratamento.

\section{- Desenvolvimento de plantas ex vitro}

Sementes de $\boldsymbol{C}$. regium (22 replicatas de 25 sementes $=550)$ imersas em $\mathrm{H}_{2} \mathrm{SO}_{4}(98 \% \mathrm{PA})$ por 120 minutos foram posteriormente lavadas com água destilada e autoclavada, colocadas em caixas do tipo gerbox contendo vermiculita e mantidas em fitotron Marconi MA1403/UR (temperatura de $27^{\circ} \mathrm{C}$ e umidade relativa de $80 \%$ ). Após germinação, plântulas com presença dos cotilédones foram transferidas para vasos de $3 \mathrm{~L}$ de capacidade contendo areia ou solo de Cerrado+esterco (Tabela 1) os quais foram depositados em casa de vegetação. As irrigações foram realizadas diariamente ao final da tarde com água sem nenhum tratamento. As plantas permaneceram em vasos por oito meses e foram avaliadas quanto à altura da parte aérea, à quantidade de folhas, ao comprimento e diâmetro da raiz, à porcentagem de plantas com raiz maior que parte aérea e peso fresco e seco da parte aérea e raiz. O delineamento experimental foi 


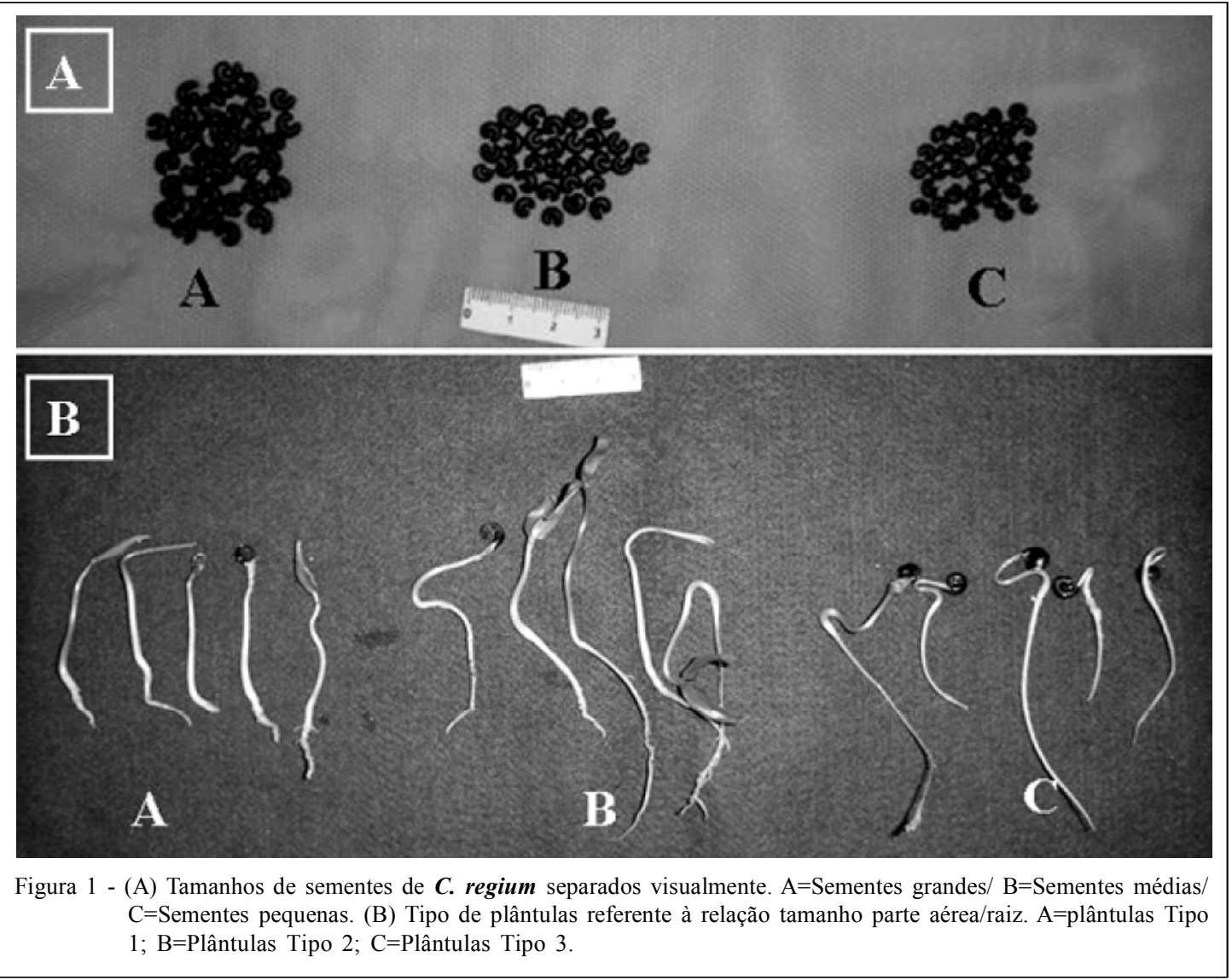

inteiramente casualizado, composto de quatro repetições com três replicatas, totalizando 12 plantas por tratamento.

Os resultados obtidos foram submetidos a ANOVA, sendo as médias comparadas pelo teste Tukey a 5\% de significância e, quando necessário, à análise de regressão com o auxílio do programa SISVAR (FERREIRA, 2005).

\section{RESULTADOS E DISCUSSÃO}

\section{- Experimentos in vitro}

Todos os tratamentos utilizados foram eficientes para eliminar contaminação superficial das sementes in vitro. Essa eficiência certamente está relacionada à característica da semente, que se apresenta lisa e sem reentrâncias, o que certamente facilitou a descontaminação. As sementes submetidas aos tratamentos com hipoclorito de cálcio, benlate e um minuto em $\mathrm{H}_{2} \mathrm{SO}_{4}$ apresentaram dormência e não germinaram no período de 40 dias. Segundo KIRIZAWA (1981), o tegumento duro das sementes de $\boldsymbol{C}$. regium dificulta a permeabilidade da água, ocasionando a dormência. Durante a assepsia, a utilização do $\mathrm{H}_{2} \mathrm{SO}_{4}$ por 40 minutos estimulou a germinação de $56,6 \%$ das sementes $( \pm 11,54)$ e o IVG foi de $0,26( \pm 0,05)$ (Tabela 2$)$.

A porcentagem de germinação e o IVG variaram de forma quadrática em função dos tempos de exposição ao ácido sulfúrico (Figuras 2A e 2B). A máxima germinação $(63 \%)$ foi obtida no tempo 146 minutos e o máximo $\operatorname{IVG}(0,78)$ foi alcançado no tempo de 144 minutos. Esse resultado com sementes germinadas in vitro corrobora com os dados obtidos por SALES et al. (2002) no qual, em papel toalha, a superação da dormência das sementes de $\boldsymbol{C}$. regium foi alcançado com escarificação química com $\mathrm{H}_{2} \mathrm{SO}_{4}$.

A porcentagem de contaminação endógena aumentou de forma linear com o incremento dos tempos de exposição do ácido sulfúrico (Figura 2C). Segundo MACCHERONI Jr. et al. (2004), a redução do pH favorece o crescimento de determinados fungos. Além disso, essa condição de estresse estimula o desenvolvimento de fungos endofíticos, que geralmente se encontram em estado de latência na semente e que passam a competir com o embrião por 
Tabela 1 - Análise dos substratos solo de Cerrado+esterco e areia quanto aos macro e micronutrientes.

\begin{tabular}{lcc}
\hline Macronutrientes & Solo Cerrado + esterco & Areia \\
\hline Matéria Orgânica $\left(\mathrm{g} \mathrm{dm}^{-3}\right)$ & 29 & 2 \\
$\mathrm{pH}$ & 6,6 & 4,4 \\
Fósforo $\left(\mathrm{mg} \mathrm{dm}^{-3}\right)$ & 239 & 6 \\
Potássio $\left(\mathrm{mmol}_{\mathrm{c}} \mathrm{dm}^{-3}\right)$ & 21,7 & 0,9 \\
Cálcio $\left(\mathrm{mmol}_{\mathrm{c}} \mathrm{dm}^{-3}\right)$ & 63 & 6 \\
Magnésio $\left(\mathrm{mmol}_{\mathrm{c}} \mathrm{dm}^{-3}\right)$ & 25 & 2 \\
Alumínio $\left(\mathrm{mmol}_{\mathrm{c}} \mathrm{dm}^{-3}\right)$ & - & - \\
Enxofre $\left(\mathrm{mg} \mathrm{dm}^{-3}\right)$ & 96 & 10 \\
Soma de Bases $\left(\mathrm{mmol}_{\mathrm{c}} \mathrm{dm}^{-3}\right)$ & 109,7 & 8,9 \\
Acidez potencial $\left(\mathrm{mmol}_{\mathrm{c}} \mathrm{dm}^{-3}\right)$ & 9 & 7 \\
Capacidade de troca catiônica & 118,7 & 15,9 \\
$\left(\mathrm{mmol}_{\mathrm{c}} \mathrm{dm}^{-3}\right)$ & & \\
Saturação de bases $(\%)$ & 92 & 56 \\
Micronutrientes & Solo Cerrado + esterco & Areia \\
Boro $\left(\mathrm{mg} \mathrm{dm}^{-3}\right)$ & 0,27 & 0,07 \\
Cobre $\left(\mathrm{mg} \mathrm{dm}^{-3}\right)$ & 4,2 & 1,4 \\
Ferro $\left(\mathrm{mg} \mathrm{dm}^{-3}\right)$ & 11 & 32 \\
Manganês $\left(\mathrm{mg} \mathrm{dm}^{-3}\right)$ & 4,1 & 3,7 \\
Zinco $(\mathrm{mg} \mathrm{dm}$ & & 2,0 \\
Sódio $\left(\mathrm{meq}^{-3}\right)$ & 7,0 & - \\
\hline
\end{tabular}

nutrientes minerais e orgânicos, presentes no endosperma dessa semente (ALMEIDA et al., 2005).

$\mathrm{O}$ tamanho das sementes não influenciou na porcentagem de germinação. Entretanto, sementes consideradas grandes $\left(A=34,08 \mathrm{~mm}^{2}\right)$ apresentaram IVG maior $(0,61)$ (Tabela 3$)$.

O tamanho da semente pode influenciar diretamente na porcentagem de germinação e índice de velocidade de germinação e essa característica pode estar relacionada à maior/menor reserva de nutrientes, água, estágio de desenvolvimento, entre outros (NIETSCHE et al., 2005; OLIVEIRA, 2006; DUARTE et al., 2006). Assim, o menor IVG das sementes pequenas sugere menor qualidade fisiológica das sementes de C. regium, já que o tamanho da semente pode ser um indicativo desse fator, no qual, sementes maiores, geralmente, possuem embriões bem formados e com maiores quantidades de reservas (CARVALHO \&
NAKAGAWA, 1983). A variabilidade de tamanho das sementes de $\boldsymbol{C}$. regium provavelmente está relacionada à rusticidade e não à domesticação da espécie.

O tamanho das sementes também interferiu na incidência de microorganismos nelas mesmas, tendo as menores $\left(A=17,99 \mathrm{~mm}^{2}\right)$ apresentado maior porcentagem de contaminação (43,3\% - Tabela 3$)$ que as de outros tamanhos. Pelo menos duas situações poderiam explicar os resultados obtidos: qualidade fisiológica da semente e aspectos evolutivos. Quanto à primeira hipótese, a falta de estudos sobre a espécie não permite inferir nada sobre isso e, do ponto de vista evolutivo, existe a possibilidade de as pequenas favorecerem relações com microorganismos endofíticos, os quais auxiliam na degradação da casca e aumentam a biodisponibilidade de nutrientes presentes nos mais diferentes substratos em que a semente se encontra, compensando a reduzida massa de endosperma que elas apresentam (STONE et al., 2000).

No experimento que avaliou o efeito do tamanho da semente na germinação de $\boldsymbol{C}$. regium, foi observada redução de $32 \%$ na taxa germinativa quando comparado ao experimento de superação da dormência. Como foi utilizado o mesmo tempo de exposição ao $\mathrm{H}_{2} \mathrm{SO}_{4}$ (120 minutos) para ambos os experimentos e o diferencial entre eles foi o tempo de armazenamento, o que sugere que sementes de $\boldsymbol{C}$. regium não são longevas. Segundo CAMILLO (2008), as sementes dessa espécie são ortodoxas, entretanto o fato de não serem longevas inviabiliza a conservação convencional em Banco de Sementes. Desse modo, a conservação em Banco de Germoplasma in vitro poderá ser uma alternativa viável para a conservação dessa espécie.

- Desenvolvimento de plantas ex vitro

A germinação de sementes de $\boldsymbol{C}$. regium originou plântulas com diferente razão entre parte aérea e raiz, as quais foram categorizadas em três tipos: 1) com 4:1 de parte aérea/raiz (representando 19,16\% das plântulas formadas); 2) com 1:2 parte aérea/raiz $(41,59 \%)$

Tabela 2 - Porcentagem de germinação, IVG*, porcentagem de contaminação exógena e endógena em função da assepsia das sementes de $\boldsymbol{C}$. regium.

\begin{tabular}{ccccc}
\hline Tratamento & Contaminação exógena (\%) & Contaminação endógena (\%) & Germinação (\%) & IVG \\
\hline Assepsia 1 & 0,00 & 0,00 & 0,00 & 0,00 \\
Assepsia 2 & 0,00 & 0,00 & 0,00 & 0,00 \\
Assepsia 3 & 0,00 & 0,00 & $56,6 \pm 11,54$ & $0,26 \pm 0,05$ \\
\hline
\end{tabular}

* IVG - Índice de Velocidade de Germinação. Avaliação no período de 40 dias. 

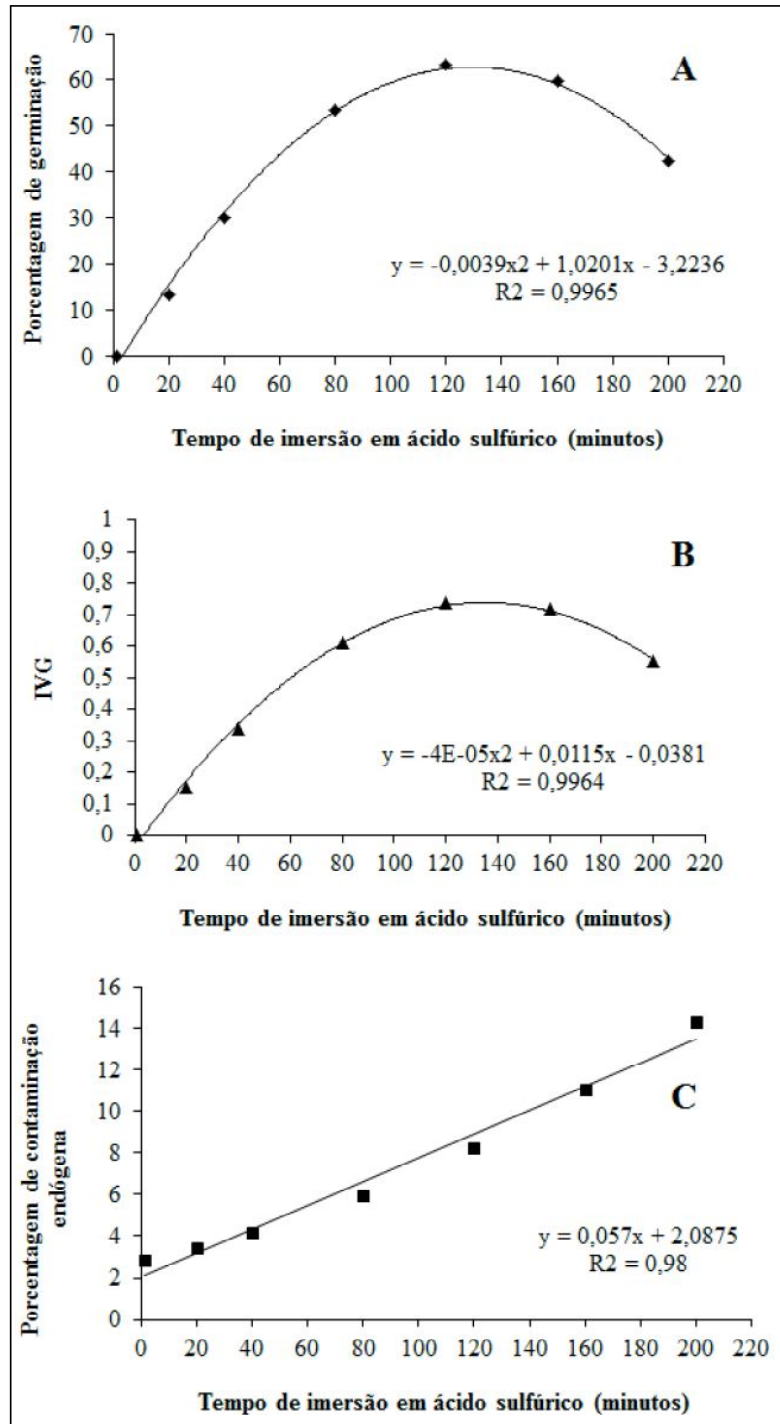

Figura 2 - Avaliação da superação da dormência de sementes de C. regium sob diferentes tempos de imersão em ácido sulfúrico concentrado. A) Porcentagem de germinação; B) Índice de velocidade de germinação (IVG); C) Porcentagem de contaminação endógena. e 3) com 1:4 parte aérea/raiz (39,25\%). Essa diferença pode estar relacionada à variabilidade genética ou morfológica das sementes, sendo necessários estudos mais aprofundados para compreender essas variações.

Quanto ao efeito do substrato no desenvolvimento das plantas, verificou-se que o solo de Cerrado+esterco proporcionou maior crescimento em altura da parte aérea, quando comparado à areia: 29,56 e 16,83cm, respectivamente. Além disso, maior peso fresco e seco de parte aérea foi obtido no mesmo substrato (Tabela 4). A melhor resposta da planta ao substrato solo de Cerrado+esterco é esperado, já que este é nutricionalmente mais favorável ao desenvolvimento que a areia e mantém a planta hidratada por maior período, pois retém mais água (Tabela 1).

As plantas mantidas em areia apresentaram maior comprimento da raiz em relação à parte aérea e o inverso ocorreu com plantas que cresceram em solo de Cerrado+esterco (Tabela 3). Maior razão entre raiz e parte aérea pode ser um indicativo da capacidade da planta de se estabelecer em ambientes secos, ou também de modificar seu desenvolvimento quando da submissão a solos com deficiência nutricional (FRIGERI, 2007). Características como essa demonstram relativo grau de plasticidade fenotípica. Dessa maneira, a alocação dos recursos dependerá da disponibilidade desse no meio. Por exemplo, em condições de solo mais seco ou mais pobre, maior quantidade de água e nutrientes devem ser obtidos. Assim, as plantas devem ter evoluído no sentido de alocar maior porção do seu crescimento a raízes do que a ramos e folhas (TILMAN, 1988). É o que acontece com $\boldsymbol{C}$. regium em seu habitat natural, o Cerrado (bioma caracterizado na sua maioria pelas secas, queimadas
1 2 3 4 5 6 7 8 9 10 11 12 13 14 15 16 17 18 19 20 21 22 23 24 25 26 27 28 29 30 31 32 33 34 35 36 37 38

Tabela 3 - Efeito do tamanho da semente de $\boldsymbol{C}$. regium no IVG*, porcentagem de germinação, de contaminação endógena e exógena.

\begin{tabular}{llccc}
\hline $\begin{array}{l}\text { Tamanho da semente } \\
\left(\text { Área }=\mathrm{mm}^{2}\right)\end{array}$ & IVG & Germinação (\%) & Contaminação endógena (\%) & Contaminação exógena (\%) \\
\hline Grande $(34,08)$ & $0,61 \mathrm{a}$ & $43,3 \mathrm{a}$ & $6,6 \mathrm{~b}$ & - \\
Média $(27,74)$ & $0,26 \mathrm{ab}$ & $26,6 \mathrm{a}$ & $6,6 \mathrm{~b}$ & - \\
Pequena $(17,99)$ & $0,14 \mathrm{~b}$ & $20,0 \mathrm{a}$ & $43,3 \mathrm{a}$ & - \\
CV \% & 46,74 & 56,66 & 30,57 & - \\
\hline
\end{tabular}

Médias não seguidas da mesma letra na coluna diferem entre si a 5\% de probabilidade pelo teste Tukey. *IVG - Índice de Velocidade de Germinação.

Ciência Rural, v.40, n.11, nov, 2010. 
Tabela 4 - Altura da parte aérea (APA), quantidade de folhas (QF), comprimento da raiz (CR) e diâmetro da raiz ( $\theta$ R), porcentagem de plantas com raiz maior que parte aérea (\%RMPA), peso fresco e seco de parte aérea (PFPA e PSPA) e raiz (PFR e PSR).

\begin{tabular}{lccccccccc}
\hline Substrato & APA $(\mathrm{cm})$ & QF & CR $(\mathrm{cm})$ & ØR $(\mathrm{cm})$ & RMPA $(\%)$ & PFPA $(\mathrm{g})$ & PSPA $(\mathrm{g})$ & PFR $(\mathrm{g})$ & PSR $(\mathrm{g})$ \\
\hline A & $16,83 \mathrm{~b}$ & $9,50 \mathrm{a}$ & $21,00 \mathrm{a}$ & $0,93 \mathrm{a}$ & $91,67 \mathrm{a}$ & $3,94 \mathrm{~b}$ & $0,71 \mathrm{~b}$ & $6,64 \mathrm{a}$ & $1,62 \mathrm{a}$ \\
S+E & $29,56 \mathrm{a}$ & $11,79 \mathrm{a}$ & $22,41 \mathrm{a}$ & $1,31 \mathrm{a}$ & $29,17 \mathrm{~b}$ & $9,54 \mathrm{a}$ & $1,87 \mathrm{a}$ & $10,37 \mathrm{a}$ & $2,09 \mathrm{a}$ \\
CV\% & 17,87 & 16,81 & 16,92 & 19,74 & 44,69 & 41,39 & 32,38 & 58,74 & 57,11 \\
\hline
\end{tabular}

Médias não seguidas da mesma letra na coluna diferem entre si a 5\% de probabilidade pela Anova ( $\mathrm{n}=12$ ). Oito meses após montagem do experimento. $\mathrm{A}=$ Areia/ $\mathrm{S}+\mathrm{E}=$ solo de Cerrado + esterco.

e deficiência nutricional do solo), no qual as raízes, armazenadoras de água, atingem um metro ou mais de profundidade e com poucos ramos (SÓLON et al., 2009).

Do ponto de vista ecológico, esses dados revelam que $\boldsymbol{C}$. regium apresenta alta adaptação a diferentes tipos de solo, pois se desenvolveu bem em solo de Cerrado+esterco e sobreviveu em areia. Isso explica a intensa dispersão da espécie nos vários tipos fitofisionômicos do Cerrado, o que garante a sua sobrevivência independente da fertilidade do solo. Vale ressaltar que foram constatados sinais de deficiência nutricional, como coloração amarela das folhas, nas plantas mantidas em areia.

Algumas características relevantes também foram observadas durante o desenvolvimento das plantas na casa de vegetação. A partir do outono, as folhas das plantas começaram a entrar em senescência e caducar e, no início do inverno, houve formação dos botões florais para plantas mantidas em ambos os tratamentos. Esses dados corroboram os estudos realizados por POPPENDIECK (1981), nos quais o autor mostrou que a floração da espécie $\boldsymbol{C}$. regium acontece na mesma época em que ela está desfolhada.

\section{CONCLUSÃO}

A partir dos resultados apresentados neste trabalho, conclui-se que é possível introduzir sementes de $\boldsymbol{C}$. regium in vitro sem contaminação e que a presença dos microorganismos está relacionada ao tamanho das sementes e ao tempo de exposição ao ácido sulfúrico. A espécie apresenta adaptabilidade a solos deficientes em nutrientes, podendo ser mantida por mais de oito meses em substrato areia sem comprometer de maneira expressiva seu crescimento. Apesar disso, recomendamos que a produção em escala de $\boldsymbol{C}$. regium seja realizada em substrato fértil, por promover plantas com maior biomassa e vigor.

\section{AGRADECIMENTOS}

À Fundação de Amparo à Pesquisa do Estado de São Paulo (FAPESP), pela bolsa de pós-graduação (Processo 2008/52719-0), financiamento de projeto (Processo 2008/ 52720-9) e à Universidade de Ribeirão Preto (UNAERP).

\section{REFERÊNCIAS}

ALMEIDA, C.V. et al. Fungos endofíticos isolados de ápices caulinares de pupunheira cultivada in vivo e in vitro. Pesquisa Agropecuária Brasileira, v.40, p.467-470, 2005. Disponível em: <www.scielo.br/pdf/pab/v40n5/24428.pdf>. Acesso em: 20 nov. 2009. doi: 10.1590/S0100-204X2005000500007.

CAMILLO, J. Germinação e conservação de germoplasma de algodão-do-campo [Cochlospermum regium (Mart. \& Schr.) Pilg.J-Cochlospermaceae. 2008. 95f. Dissertação (Mestrado em Ciências Agrárias) - Curso de Ciências Agrárias, Universidade de Brasília, DF.

CARVALHO, N.M.; NAKAGAWA, J. Sementes: ciência, tecnologia e produção. Campinas: Cargill, 1983. 429p.

COELHO, M.F.B. et al. Condições de luz e temperatura na germinação de sementes de algodão do campo [Cochlospermum regium (Schrank) Pilger-Bixaceae]. Revista de Biologia Neotropical, v.5, n.2, p.23-31, 2008. Disponível em: <http:/ /www.revistas.ufg.br/index.php/RBN/article/view/9814/6704>. Acesso em: 16 maio, 2010.

DUARTE, E.F. et al. Germinação e vigor de sementes de cagaita (Eugenia dysenterica Mart. Ex. DC.) em função de seu tamanho e tipo de coleta. Pesquisa Agropecuária Tropical, v.36, p.173-179, 2006. Disponível em: <http://www.revistas.ufg.br/ index.php/pat/article/view/2043/2051>. Acesso em: 11 out. 2009.

FERREIRA, D.F. Sisvar 5.1 - Análises estatísticas por meio do Sisvar para Windows. 2005. Lavras: Universidade Federal de Lavras. Download gratuito. Disponível em: $<\mathrm{http}: / /$ www.dex.ufla.br/ danielff/softwares.htm $>$. Acesso em: 10 maio, 2009.

FRIGERI, R.B.C. Relação entre raiz e parte aérea de plântulas de espécies tropicais sob diferentes níveis de radiação solar. 2007. 152f. Tese (Doutorado em Biologia Vegetal) - Curso de Biologia Vegetal, Universidade Estadual de Campinas, SP. 
KIRIZAWA, M. Contribuição ao conhecimento morfoecológico e do desenvolvimento anatômico dos órgãos vegetativos e de reprodução de Cochlospermum regium (MART. e SCHR.) PILGER - Cochlospermaceae. 1981. 437f. Tese (Doutorado em Ciências) - Curso de Ciências Biológicas, Universidade de São Paulo, SP.

MACCHERONI Jr, W. et al. Secreção de enzimas mediada pelo $\mathrm{pH}$ do ambiente em isolados patogênicos e endofíticos do fungo Colletotrichum. Scientia Agricola, v.61, n.3, p.298-302, 2004. Disponível em: <http://www.scielo.br/pdf/sa/v61n3/ a10v61n3.pdf>. Acesso em: 20 nov. 2009. doi: 10.1590/ S0103-90162004000300010.

MURASHIGE, T.; SKOOG, F. A revised medium for rapid growth and bioassays with tobacco tissue cultures. Physiology Plant, v.15, n.3, p.473-497, 1962.

NIETSCHE, S. et al. Tamanho da semente e substratos na germinação e crescimento inicial de mudas de cagaiteira. Ciências Agrotécnicas, v.28, p. 1321-1325, 2005. Disponível em: < www.editora.ufla.br/revista/28_6/art14.pdf>. Acesso em: 12 out. 2009.

OLIVEIRA, I.V.M. Influência do tamanho-peso da semente na precocidade de emergência de bacuripari (Rheedia gardneriana). Revista Caatinga, v.19, p.387-390, 2006. Disponível em: $<$ http://periodicos.ufersa.edu.br/index.php/sistema/article/ viewFile/96/68>. Acesso em: 15 out. 2009.

POPPENDIECK, H.H. Flora neotropica monograph, 1981. Disponível em: <http://www.jstor.org/stable/4393745>. Acesso em: 20 jul. 2009.
SALES, D.M. et al. Superação da dormência por ácido sulfúrico em sementes de algodão do campo [Cochlospermum regium (Mart. \& Schr.) Pilg.]-Cochlospermaceae). Revista Brasileira de Plantas Medicinais, v.4, n.2, p.65-71, 2002. Disponível em: <http://www.ibb.unesp.br/servicos/publicacoes/rbpm/ pdf_v4_n2_2002/artigo_11_v4_n2.pdf>. Acesso em: 20 ago. 2008 .

SÓLON, S. et al. O gênero Cochlospermum com ênfase nos aspectos etnobotânicos, farmacológicos, toxicológicos e químicos de Cochlospermum regium (Mart. Et. Schr.) Pilger. Revista Eletrônica de Farmácia, v.6, n.3, p.1-22, 2009. Disponível em: <http://www.revistas.ufg.br/index.php/REF/ article/viewArticle/7649>. Acesso em: 10 fev. 2010.

SOUZA, C.D.; FELFILI, J.M. Uso de plantas medicinais na região de Alto Paraíso de Goiás, GO, Brasil. Acta Botanica Brasílica, v.20, p.135-142, 2006. Disponível em: <http:// www.scielo.br/pdf/abb/v20n1/13.pdf>. Acesso em: 26 jul. 2009. doi: $10.1590 / \mathrm{S} 0102-33062006000100013$.

STONE, J.K. et al. An overview of endophytic microbes: endophytism defined. In: BACON, CW.; WHITE Jr, JF. Microbial endophytes. New York: Marcel Dekker, 2000. p.3-29.

TILMAN. D. Plant strategies and the dynamics and structure of plant communities, 1988. Disponível em: < http://books.google.com.br>. Acesso em: 27 jul. 2010.

TRESVENZOL, LM. et al. Estudo sobre o comércio informal de plantas medicinais em Goiânia e cidades vizinhas. Revista Eletrônica de Farmácia, v.3, p.23-28, 2006. Disponível em: $<$ http://www.revistas.ufg.br/index.php/REF/article/viewFile/ 2070/2013>. Acesso em: 05 set. 2009. 